\title{
Asymmetric Ring Opening of Epoxides Catalyzed by Novel Heterobimetallic Schiff-Bases Containing Transition Metal Salts
}

\author{
Rahul B Kawthekar, Wen-tao Bi, and Geon-Joong Kim \\ Fine Iaterial Symhesis Laboratory, Department of Chemical Engineering, Inha Linwersity, Incheon $402-751$, Korea \\ E-mail kimgiainha.ac.kr \\ Received.tigust 1, 2007
}

\begin{abstract}
An enantioselective ring opening of racemic tenminal epoxides has been achieved by using heterobimetallic cobalt salen complexes with variety of nucleophiles. They were proven to be highly enantioselective and reactive for the sỵthesis of valuable chiral building blocks in enantio-riched fonns up to $98 \%$ ee.
\end{abstract}

Key Words : Kinetic resolution. Ring opening reactions. Heterobimetallic catalyst. Chiral intermediate

\section{Introduction}

Asymmetric catalysis is an attractive strategy for the production of valuable chiral building blocks as an academic and pharmaceutical interest. Specifically: hydrolytic kinetic resolution (HKR) is one of the most important reactions to synthesize an enantiomerically enriched terminal epoxides. ${ }^{1}$ In our previous research. we have introduced that dimeric chiral salens having 13 group metal salts such as $\mathrm{AlCl}_{3}$ or $\mathrm{GaCl}_{\hat{3}}$ displayed good enantioselectivity and reactivity for the asymmetric kinetic resolution (AKR) of terminal epoxides." More recently. Shibasali et al. reported the heterobimetallic asymmetric catalysis in which the two different metal plays different role to enhance the reactivity of both reacting partners. ${ }^{3}$ In 1968 . Gnuber's group demonstrated that the preparation of both homo- and heterodinuclear complexes contained similar or dissimilar transition metal salts. ${ }^{4}$ On the basis of this report our idea was to design of chiral $\mathrm{Co}$ (salen) catalyst that contained transition metal salts as remarkably efficient catalyst.

In this paper. addition of nucleophiles. such as water. phenols and $\mathrm{CO}_{2}$ to several terminal epoxides was examined using novel heterobimetallic Co (salen) cataly sts (Scheme 1)

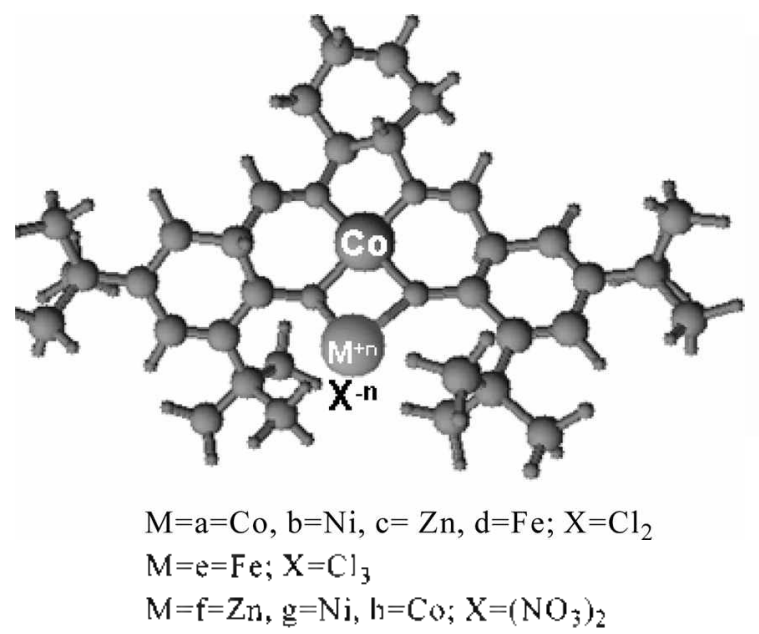

Scheme 1. Cobalt salen catalyst with similar and dissimilar metals. to obtain chiral building blocks. However. these types of catalysts have never been explored in the asymmetric synthesis: especially in enantioselective ring opening of tenninal racemic epoxides to obtain the variety of chiral intermediates.

Wide ranges of synthetic application of our catalysts in AKR are readily envisaged. Surprisingly very high catalytic activity and enantioselectivity were obtained not only for the special reaction but also for many other AKR reactions applied in this study. and were dependent on the type of transition metal salts combined to the cobalt-salens with the different nucleophiles. It has been already established that oxygen atoms of the metal complexes of the Schiff bases are able to coordinate to the transition metals to form bi- and trinuclear complex.

\section{Results and Discussion}

A series of chiral Co (salen) complexes were screened in order to evaluate the reactivity and perfonnance of chiral catalysts in $\mathrm{HKR}$ of epicholorohydrin $(\mathrm{ECH})$ with $\mathrm{H}_{2} \mathrm{O}$ as a model reaction and the results are summarized in Table 1. From this comparison. the catalyst a. e. f. and $\mathbf{h}$ exhibited high enantioselectivity with good yield in HKR reaction (Table 1. entries 1, 5, 6. and 8). As expected. the HKR of racemic styrene oxide. phenyl glycidyl ether. and methyl glycidyl ether underwent resolution with $96-99 \%$ ee of corresponding products under solvent-free condition (Table 1. entries 9-11). In each instance. the reactions carried out at ambient temperature were completed within 3-12 h. Furthermore. catalyst a and e were identified as the most effective among those evaluated although $\mathbf{f}$ and $\mathbf{h}$ were useful. Kinetic studies in HKR reaction using complex a revealed the reaction pathway involving the coorperative. intramolecular bimetallic catalysis.

(S)- $\beta$-Hydroxy- $\gamma$-butyrolactone is known as a satiety agent as well as a potential intermediate for variety of neuroleptic drugs. ${ }^{6}$ Encouraged with the initial success in the HKR reaction. the synthesis of $(\mathrm{S})-(-)-\beta$ hyddroxy- $\gamma$-butyrolactone has been accomplished by employing HKR of methyl-4oxobutanoate using $0.5 \mathrm{~mol} \%$ of catalyst a to get chiral $3.4-$ 
Table 1. Hydrolytic kinetic resolution (HKR) of terminal epoxides

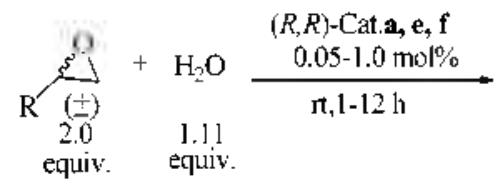

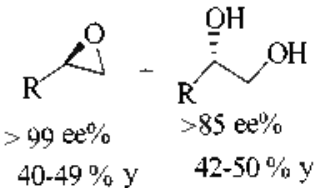

$\mathrm{R}=-\mathrm{CH}_{2} \mathrm{Cl},-\mathrm{Ph},-\mathrm{CH}_{2} \mathrm{OPh},-\mathrm{CH}_{2} \mathrm{OCH}_{3}$

\begin{tabular}{ccccc}
\hline Entry $^{a}$ & Catalyst & $\mathrm{Mol}^{b}$ & Tune (h) & $\% \mathrm{ee}^{c}$ \\
\hline 1 & $\mathbf{a}$ & 0.3 & 3 & 99 \\
2 & $\mathbf{a}$ & 0.05 & 12 & 98 \\
3 & $\mathrm{e}$ & 0.3 & 5 & 97 \\
4 & $\mathrm{e}$ & 0.5 & 2 & 99 \\
5 & $\mathrm{e}$ & 0.05 & 12 & 97 \\
6 & $\mathbf{f}$ & 0.3 & 3 & 99 \\
7 & $\mathbf{f}$ & 0.5 & 1 & 99 \\
8 & $\mathbf{f}$ & 0.05 & 12 & 99 \\
$9^{7}$ & $\mathbf{a}$ & 0.3 & 5 & 94 \\
$10^{e}$ & $\mathbf{a}$ & 1.0 & 7 & 96 \\
$11^{f}$ & $\mathbf{a}$ & 0.3 & 3 & 99 \\
\hline
\end{tabular}

"Epichlorohdrine used as a reactant from entry 1 to 8 . "Catalyst loading on a per $\mathrm{Co}$ basis relative to racemic epovides. "ee "o was deternimed by chiral chiral GC. "Phenyl glycidyl ether is used as a reactant. "Styrene oxide used as a reactant. ${ }^{\prime}$ Metlyyl glycidyl ether is used as a reactant.

dilnydroxy butanoate with $99 \%$ ee. Further. the cyclization of 3,4-dihydroxy butanoate was performed by using catalytic anount trifluoroacetic acid in methylene chloride (MC) as shown in Scheme 2.

To widen the scope, catalyst a was tested in the HKR of ( \pm ) 1-[p-(cyanomethyl) phenosy $]-2,3-$ epoxypropane to obtain chiral epoxides. In this case. the nitrile substituted epoxides at para position displayed a high ee of chiral epoxides, which are vital intermediates for the synthesis of $S$ (-)atenolol. ${ }^{7.9}$ Transformation to chiral atenolol was simply achieved by asymmetric ring opening (ARO) of chiral $1-[p$ (cyanomethyl) phenosy]-2.3-eposypropane with isopropyl amine, followed by hydration of nitrile groups as shown in Scheme 3. This is one of the promising strategies using chiral catalyst in our current study.

Spurred with the success of HKR of aromatic epoxides, another important reaction, and direct ring opening of terminal epoxides with phenols as nucleophile catalyzed by chiral cobalt complexes and the results are summarized in Table 2. As can be seen from Table 2, a series of terminal epoxides reacts with various phenol derivatives to offer corresponding optically enriched $\alpha$-arylosy alcohols with $84-99 \%$ ee in $38-43 \%$ yields. To further explore the utility of chiral cobalt salen catalysts for the enantioselective ring opening of terminal epoxides by phenols. $]-[p-[$ (butosycarbonyl) methyl] phenoxy]-2.3-epoxypropane was evaluated as a substrate for the synthesis of atenolol using catalyst a through kinetic resolutions. The ARO of racemic ECH proceeded perfectly both in tenns of enantioselectivity and reactivity. The reaction was completed within $8 \mathrm{~h}$ to afford corresponding enantiopure $\alpha$-aryloxy alcohols witl $98 \%$ ee

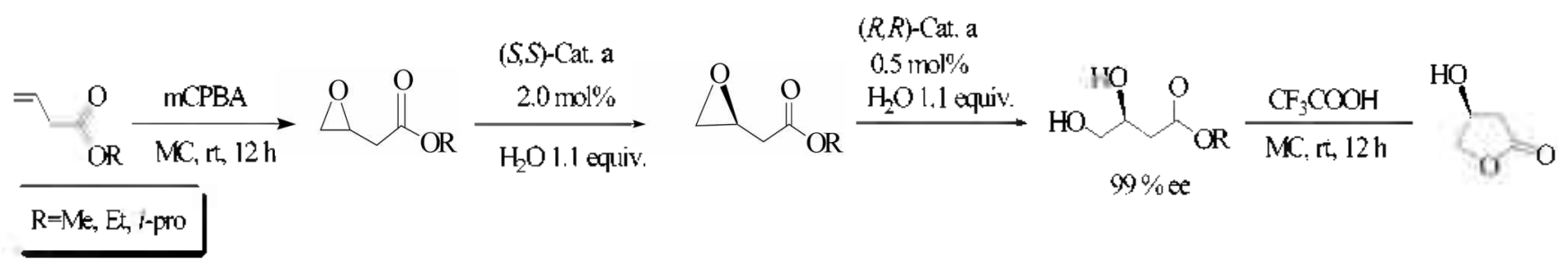

Scheme 2. Synthesis of $S(-)-\beta$ Hydroxy- $y$-butyrolactone.<smiles>N#CCc1ccc(OCC2CO2)cc1</smiles>

$( \pm)$

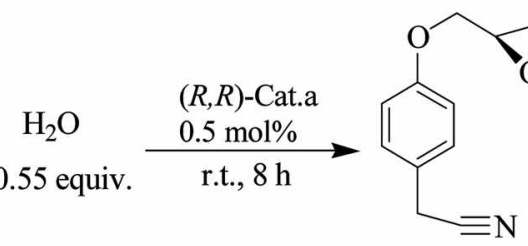<smiles>[R]C(C)N</smiles><smiles>CCCOC(=O)Cc1ccc(OC[C@@H](O)CCl)cc1</smiles><smiles>CC(C)NC[C@H](O)COc1ccc(CC#N)cc1</smiles><smiles>CCCOC(=O)Cc1ccc(OC[C@@H](O)CNC(C)O[Na])cc1</smiles><smiles>CC(C)NC[C@H](O)COc1ccc(CC(N)=O)cc1</smiles>

1.00 equiv.

2.22 equiv.

Scheme 3. Synthesis of $S(-)$ Atenolol using cobalt salen a ria kinetic resolution. 
Table 2. Asymmetric ring opening of terninal epoxides with phenols catalyzed by heterometallic complexes

\begin{tabular}{|c|c|c|c|c|c|c|}
\hline $1.0 \mathrm{e}$ & quiv & $\mathrm{R}^{2} \frac{\mathrm{s}_{( \pm)}^{\mathrm{O}}}{( \pm)}$ & $\begin{array}{r}(R, R) \text {-cat } \\
1-2 \text { mol }\end{array}$ & & \multicolumn{2}{|c|}{$\begin{array}{l}\mathrm{R}_{1} \\
84-99 \% \text { ee } \\
38-43 \% \text { yield }\end{array}$} \\
\hline Entry & $\mathrm{R}^{1}$ & $\mathrm{R}^{2}$ & Catalyst & $\mathrm{Mol} \%^{\sigma}$ & $\begin{array}{c}\text { Time } \\
{[\mathrm{h}]}\end{array}$ & $\begin{array}{c}\text { ee } \%^{b} \\
\text { (vield, } \%{ }^{\circ} \text { ) }\end{array}$ \\
\hline 1 & $\mathrm{H}$ & $\mathrm{CH}_{2} \mathrm{Cl}$ & $\mathbf{a}$ & 1 & 8 & $98(41)$ \\
\hline 2 & $\mathrm{H}$ & $\mathrm{CH}_{2} \mathrm{Cl}$ & $\mathbf{f}$ & 1 & 8 & $96(+1)$ \\
\hline 3 & $3-\mathrm{Cl}$ & $\mathrm{CH}_{2} \mathrm{Cl}$ & f & 1 & 9 & $98(40)$ \\
\hline 4 & $3-\mathrm{Cl}$ & $\mathrm{CH}_{2} \mathrm{Cl}$ & f & 2 & 9 & $99(42)$ \\
\hline 5 & $3-\mathrm{Cl}$ & $\mathrm{C}_{6} \mathrm{H}_{5}-\mathrm{O}-\mathrm{CH}_{2}$ & $\mathbf{a}$ & 2 & 12 & $84(38)$ \\
\hline 6 & $3-\mathrm{Cl}$ & $\mathrm{C}_{6} \mathrm{H}_{5}-\mathrm{O}-\mathrm{CH}_{2}$ & f & 2 & 12 & $85(39)$ \\
\hline 7 & $3-\mathrm{CH}_{2}$ & $\mathrm{CH}_{2} \mathrm{Cl}$ & $\mathbf{a}$ & 2 & 8 & $92(43)$ \\
\hline 8 & $3-\mathrm{CH}_{2}$ & $\mathrm{CH}_{2} \mathrm{Cl}$ & $\mathbf{f}$ & 2 & 8 & $94(42)$ \\
\hline 9 & $3-\mathrm{CH}_{2}$ & $\mathrm{CH}_{2} \mathrm{Cl}$ & $\mathbf{f}$ & 1 & 8 & $94(41)$ \\
\hline
\end{tabular}

"Catalyst loading on a per Co basis relative to racemic epoxides. "ee ".o of ring opened product was determined by chiral HPLC:GC. 'Isolated yield of ring opened product on the basis of racemic epoxides.

Table 3. Asymmetric ring opening of ( \pm ) $1-[p$-(cyanomethyl) phenoxy]-2,3-epoxy propane with isopropvl amine catalyzed by heterometallic complexes

\begin{tabular}{|c|c|c|c|c|c|}
\hline & $=\mathrm{N}$ & & & $\equiv \mathrm{N}$ & \\
\hline Entry & Catalyst & $\mathrm{Mol} \%{ }^{a}$ & Solvent & Conv \% & ee $\%$ \\
\hline l & a & 5 & TBME & 30 & 96 \\
\hline 2 & f & 5 & TBME & 34 & 95 \\
\hline 3 & $\mathrm{f}$ & 5 & $\mathrm{MeCN}$ & 26 & 95 \\
\hline 4 & h & 5 & TBME & 26 & 89 \\
\hline
\end{tabular}

"Catalyst loading on a per Co basis w.r.t to racemic epoxides. ${ }^{b}$ ee 0.0 of product was deternined by chiral HPLC.

in $40 \%$ yields as shown in Scheme 3. To the best of our knowledge. we have first evaluated the direct opening of epoxides in case of chiral atenolol.

Interestingly. the kinetic resolution of $( \pm)$ 1-[p-(cyanomethyl) phenoxy]-2.3-epoxypropane (Table 3) and ( \pm )glycidyl 1-napthyl ether with isopropyl amine led to highly enriched atenolol or propranolol in presence of a in a onepot reaction. As a special case. catalyst a was also effective in the ARO reaction of epoxide with $\mathrm{NH}_{2}-\mathrm{Boc}$ as shown in Scheme 4 . The practical utility of AKR of naphthyl glycidyl ether with $\mathrm{NH}_{2}-$ Boc may be focused on the synthesis of propranolol as reported by Bartoli $t t$ al $^{1{ }^{11}}$

In recent year. the coupling reaction of carbon dioxide and epoxides to form chiral cyclic carbonates has received much attention. ${ }^{11.12}$ The chiral propylene carbonate is the crucial intermediate in the synthesis of Tenofovir as anti HIV/AIDS drugs. ${ }^{\text {la }}$ Chiral propylene carbonates are prepared by cyclization of chiral diols with triphosgene or by enzyme-

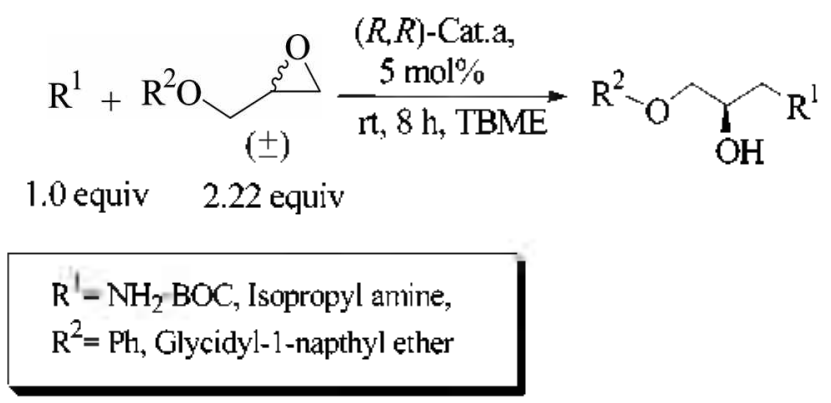

Scheme 4. Aminolytic kinetic resolution by using $(R, R)$-catalyst a.

Table $4 \mathrm{CO}_{2}$ coupling reaction with racemic propylene oxide

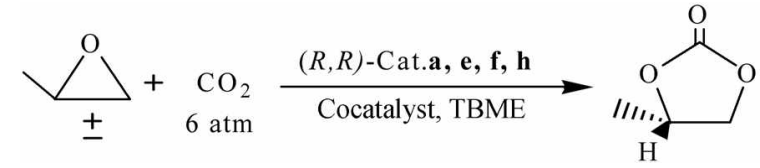

\begin{tabular}{|c|c|c|c|c|}
\hline Entry & Catalyst & Cocatalyst & $\mathrm{PC}[\mathrm{e} \%]$ & Yield, \% \\
\hline $1^{t h}$ & a & None & 89 & 25 \\
\hline $2^{c}$ & a & IBACl & 54 & 19 \\
\hline 3 & a & IBACl & 80 & 40 \\
\hline $4^{d}$ & a & [EMlm] $\mathrm{OH}$ & 63 & 32 \\
\hline 5 & a & $1 \mathrm{BAOH}$ & 79 & 39 \\
\hline 6 & $\mathbf{a}$ & $\mathrm{K}_{2} \mathrm{CO}_{3}$ & 88 & 23 \\
\hline $7^{\circ}$ & a & {$[\mathrm{BMIm}] \mathrm{Br}$} & 60 & 25 \\
\hline 8 & $\mathrm{~h}$ & IBACl & 78 & 33 \\
\hline 9 & h & IBACl & 83 & 43 \\
\hline $10^{g}$ & h & IBACl & 73 & 26 \\
\hline 11 & e & $\mathrm{IBACl}$ & 68 & 19 \\
\hline 12 & e & $\mathrm{IBAOH}$ & 46 & 14 \\
\hline $13^{n}$ & $\mathbf{f}$ & None & 90 & 29 \\
\hline 14 & f & IBACl & 83 & 45 \\
\hline $15^{\prime}$ & $f$ & IBACl & 85 & 44 \\
\hline $16^{1}$ & $\mathbf{f}$ & {$[\mathrm{BMIm}] \mathrm{OH}$} & 77 & 33 \\
\hline 17 & $\mathbf{f}$ & $\mathrm{K}_{2} \mathrm{CO}_{3}$ & 89 & 23 \\
\hline 18 & f & {$[\mathrm{BMIm}] \mathrm{Br}$} & 65 & 25 \\
\hline
\end{tabular}

The molar ratio used for reaction is POCat:Co-cat $1: 0.001: 0.0005$. b.h The reaction performed without co-catalyst. "Keaction performed under

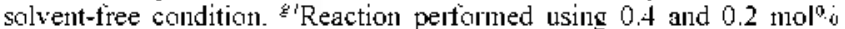
catalst respectively: $[\mathrm{EMIm}] \mathrm{OH}=1$-ethy:-3-methylimidazolium hydroxide. ${ }^{e}[\mathrm{BMIm}] \mathrm{Br}=1$-Ethy'-3-methy limidazolium bromide. '[BMIm]$\mathrm{OH}=1-\mathrm{Bu}-3-$ methylimidazolium liydroxide.

mediated enantioselective hydrolysis of racemic cyclic carbonates. $^{13,14}$ To avoid the use of toxic triphosgene in synthesis, the chemical fixation of $\mathrm{CO}_{2}$ onto epoxides using bimetallic asymmetric catalysis is the most promising alternatives to prepare the corresponding five-member chiral propylene carbonates. ${ }^{13 \cdot 16}$ The bimetallic catalytic addition of epoxides to $\mathrm{CO}_{2}$ represents nontoxic, nonflanmable and commercially useful methodology in this study. As a part of ongoing development of $\mathrm{Co}$ (salen) catalytic system, we had much interest in the possibility of employing the newly synthesized Co (salen) complexes for direct synthesis of optically active cyclic carbonates from the racemic terminal epoxides. As can be seen from Table 4 , we have found a. $\mathbf{h}$ and $f$ to be much more active and selective than the 
analogous $\mathrm{Co}^{\mathrm{II}}$ (salen) or $\mathrm{Co}^{\mathrm{III}}$ (salen) comple ${ }^{1 . .13}$ in the binary catalytic system. Decreasing the loading amount of catalyst and the addition of quaternary ammonium salts as an additive increased the enantiomeric purity of product. The reaction without quaternary ammonium halide exhibited higher enantioselectivity but less in yield. However, the activity was greatly enhanced with addition of catalytic amount of quaternary ammonium halides. To the best of our knowledge, our catalytic system showed the highest enantioselectivity for the cycloaddition of $\mathrm{CO}_{2}$ to epoxides under mild conditions among the reported cataly sts. ${ }^{12}$

\section{Conclusion}

We have explored the new chiral Co (salen) complexes efficient for HKR, ARO of terminal epoxides by various nuclophiles, and the enantioselective cycloaddition of $\mathrm{CO}$ : to eposypropane. New salen complexes applied in this work has displayed a high enantiosective inducing ability in each reaction. providing more than $98 \%$ ee in high product yields. We have developed new route to optically pure atenolol synthesis via AKR of racemic ECH with $p$-hydroxyphenyl acetic acid as nucleophiles, and in addition via HKR of $( \pm)$ 1 -[ $p$-(cynomethyl)phenoxy]-2.3-epoxypropane. Our salen catalysts also showed a very unique activity in the kinetic resolution of epoxides with amine conpounds such as isopropyl amine and $\mathrm{NH}_{2}-\mathrm{Boc}$. Efforts are underway to elucidate the mechanistic details and to explore other applications of the catalyst systems

\section{Experimental}

All ${ }^{1} \mathrm{H}-\mathrm{NMR}$ and ${ }^{13} \mathrm{C}$-NMR were recorded using OXFERD$400 \mathrm{MHz}-\mathrm{NMR}$ instrument. Chemical shifts for proton were reported in part per million downfield from tetramethyl silane (TMS) as an internal reference at ambient temperature. DMSO- $d_{6 .} \mathrm{CDCl}_{3}$ and $\mathrm{D}_{2} \mathrm{O}$ solvents were used for NMR analysis. Infrared spectra (IR) were measured with a Perkin-Elmer Spectrum 2000 Explorer FT-IR spectrometer. Optical rotation measurements were conducted using a JASCO DIP 370 digital polarimeter. Chiral HPLC analyses were performed on a YOUNGLIN instrument using a Chiralcel $^{\sqrt{3}} \mathrm{OD}$ colunn $(24 \mathrm{~cm} \times 0.46 \mathrm{~cm}$ i.d Chiral Technologies, Inc.) and Regis $(S, S)$ Whelk-Ol at $254 \mathrm{~nm}$. Chiral Gas chromatographic analy'ses were performed on HewlettPackard 5890 Series II instrument equipped with a FID detector using a chiral column (CHIRALDEX $\gamma$-TA and $\alpha$ TA. $20 \mathrm{~m} \times 0.25 \mathrm{~mm}$ i.d. (Astec) and a HP 3396 integrator with HP Chem Station software for data analy sis.

$(R, R)$ - $N, N$-Bis(3,5-tert-butylsalicylidene)-1,2-cyclohexanediamine $\mathrm{Co}-\mathrm{CoCl}_{2}$ (a). To a solution of $(R, R)-N, N-$ bis $(3,5-$ tert-butylsalicylidene)-1.2-cyclohexanedianine $\mathrm{C}{ }^{\mathrm{II}}$ salen complex ( 1.00 g. 0.0016 mole. 1 equiv.) in $15 \mathrm{~mL}$ THF was added $\mathrm{CoCl}_{2} \cdot 6 \mathrm{H}_{3} \mathrm{O}(0.473 \mathrm{~g}, 0.0019$ mole. 1.2 equiv. $)$ in 5 $\mathrm{mL}$ THF. The solution was stirred in open atmosphere at room temperature for $2 \mathrm{~h}$ and the solvent was removed in vacuo. The residue was dissolved in $\mathrm{MC}$ and the solution was only collected to remove unreacted excess metal salts: The product a was obtained as a dark brown solid after removal of solvent in vacto ( 1.19 g. 0.00162 mole. $98 \%$ yield).

${ }^{1} \mathrm{H}-\mathrm{NMR}\left(400 \mathrm{MHz}, \mathrm{DMSO}-\mathrm{d}_{i}\right): \delta 1.28(\mathrm{~s}, 18 \mathrm{H}) .1 .50-$ 1.62 (m. 2H). $1.72(\mathrm{~s}, 18 \mathrm{H}) .1 .80-1.95(\mathrm{~m}, 4 \mathrm{H}) .1 .96-1.98$ (m. $2 \mathrm{H}) .3 .1-3.2(\mathrm{~m}, 2 \mathrm{H}) .3 .5-3.7(\mathrm{~m}, 2 \mathrm{H}), 7.40$ (d. $J=2.4$ Hz. $2 \mathrm{H}$ ). 7.45 (d, $J=2.4 \mathrm{Hzm} 2 \mathrm{H}$ ). 7.78 (s. $2 \mathrm{H}$ ). ${ }^{13} \mathrm{C}$-NMR (400 MHz. DMSO-d 6 ) $\delta 25.8 .31 .1,32.2,36.4 .67 .6,69.9$. 119.2, 129.3, 136.4. 142.3. 162.5. FT-IR $(\mathrm{KBr}):\left[\mathrm{cm}^{-1}\right]$ $=2954.2866,1637.1611 .1525,1465,1369.1249 .1202$. $1165,1023,925.835,782.754 .636,595$. Anal. Cal. For $\mathrm{C}_{36} \mathrm{H}_{52} \mathrm{Cl}_{2} \mathrm{Co}_{2} \mathrm{~N}_{2} \mathrm{O}_{2}: \mathrm{C}, 58.94: \mathrm{H}$. 7.14: Cl. 9.67; Co. 16.07: N. 3.82: O. 4.36 Found: C. 59.03: H. 7.00; Cl. 9.52; Co, 16.00: N. 3.79: O. 4.45 .

$(R, R)$ - $N, N$-Bis(3,5-tert-butylsalicylidene)-1,2-cyclohexanediamine $\mathrm{Co}^{-} \mathrm{FeCl}_{3}(\mathrm{e})$. To a solution of $(R, R)-N, N$-bis(3.5tert-butylsalicylidene)-1,2-cyclohexanediamine salen $\mathrm{Co}^{\mathrm{II}}$ complex ( $1.00 \mathrm{~g} .0 .0016$ mole. 1.0 equiv.) in $15 \mathrm{~mL}$ THF was added $\mathrm{FeCl}_{\mathfrak{3}}(0.322$ g. 0.0019 mole, 1.2 equiv.) in $5 \mathrm{~mL}$ THF. The residue was dissolved in MC and the solution was filtered to remove excess metal salts: The product e was obtained as a dark brown solid after removal of solvent in vacho (1.20 g. 0.00150 mole, $95 \%$ yield). ${ }^{3} \mathrm{H}-\mathrm{NMR}(400$ $\left.\mathrm{MHz}, \mathrm{DMSO}-\mathrm{d}_{6}\right): \delta 1.27$ (s. 18H). $1.55-1.68$ (m. 2H), 1.71 $(\mathrm{s}, 18 \mathrm{H}), 1.86-1.95(\mathrm{~m} .4 \mathrm{H}), 1.96-2.20$ (m. $2 \mathrm{H}) .3 .0-3.2(\mathrm{~m}$, $2 \mathrm{H}) .3 .5-3.8(\mathrm{~m}, 2 \mathrm{H}) .7 .4 \mathrm{l}(\mathrm{d}, J=2.4 \mathrm{~Hz} .2 \mathrm{H}), 7.59(\mathrm{~d}, J=$ $2.4 \mathrm{~Hz} .2 \mathrm{H}) .7 .76(\mathrm{~s}, 2 \mathrm{H}) .{ }^{13} \mathrm{C}-\mathrm{NMR}\left(400 \mathrm{MHz}, \mathrm{DMSO}-\mathrm{d}_{6}\right)$ $\delta .24 .5,25.8 .29 .3 .30 .9,31.5 .35 .7 .69 .21$. 119.3. 128.4. 134.1, 142.3. 158.5. 162.1.164.8. FT-IR (KBr): $\left[\mathrm{cm}^{-1}\right]$ $=2954.2866,1634.1609,1511.1459,1365.1251 .1208$, 1169, $1035,985,834,785,734.640,597$. Anal. Cal. For $\mathrm{C}_{36} \mathrm{H}_{52} \mathrm{Cl}_{3} \mathrm{CoFeN}_{2} \mathrm{O}_{2}: \mathrm{C} .56 .90$ : H. 7.10; $\mathrm{Cl}, 13.62 ; \mathrm{Co}, 7.55$ : Fe, 7.15: N, 3.59: O, 4.10 Found: C, $56.85 ; \mathrm{H} .7 .13 ; \mathrm{Cl}$, 13.66: Co, 7.60; Fe, 7.20; N. 3.62: O. 4.09.

$(R, R)$ - $N, N$-Bis(3,5-tert-butylsalicylidene)-1,2-cyclohexanediamine $\mathbf{C o}-\mathbf{Z n}\left(\mathrm{NO}_{3}\right)_{2}$ (f). To a solution of $(R \cdot R)-N, N$-bis (3.5-tert-butylsalicylidene)-1.2-cyclohexanediamine salen Co ${ }^{\text {II }}$ complex ( 1.00 g. 0.0016 mole. 1.0 equiv) in $15 \mathrm{~mL}$ THF was added $\mathrm{Zn}\left(\mathrm{NO}_{2}\right)_{2} 6 \mathrm{H}_{2} \mathrm{O}(0.591$ g. 0.0019 mole. 1.2 equiv.) in $5 \mathrm{~mL}$ THF. The solution was stirred at open atmosphere at room temperature for $2 \mathrm{~h}$, and the solvent was removed in vacuo. The residue was dissolved in MC and filtered to remove unreacted metal salts: The product $\mathbf{f}$ was obtained as a dark brown solid after removal of solvent in vacuo (1.26 g. 0.00160 mole. $96 \%$ yield).

${ }^{1} \mathrm{H}-\mathrm{NMR}\left(400 \mathrm{MHz}\right.$. DMSO-d ) $^{-} \delta=1.25$ (s. 18H), 1.541.64 (m. 2H). $1.71(\mathrm{~s}, 18 \mathrm{H}) .1 .80-1.90(\mathrm{~m}, 4 \mathrm{H}) .1 .95-1.97$ (m. 2H). 3.1-3.2 (m, 2H). 3.5-3.6 (m. 2H). 7.40 (d. $J=2.4$ Hz. $2 \mathrm{H}) .7 .42$ (d. $J=2.4 \mathrm{~Hz}, 2 \mathrm{H}) .7 .74$ (s. $2 \mathrm{H}) .{ }^{13} \mathrm{C}-\mathrm{NMR}$ (400 MHz. DMSO-d 6 ): $\delta=24.3 .25 .1,29.5,30.5 .31 .5 .33 .5$. 67.0. 69.2, 118.5, 128.6, 129.0, 135.8, 141.7, 161.8, 164.4. FT-IR $(\mathrm{KBr}):\left[\mathrm{cm}^{-1}\right]=2950,2863.1635 .1608,1523.1461$, 1361. 1253. 1200. 1172. 1026.926. 833, 783. 744, 640. 597 Anal. Cal. For $\mathrm{C}_{36} \mathrm{H}_{32} \mathrm{CoN}_{4} \mathrm{O}_{8} \mathrm{Zn}$ : C, 54.52; H, 6.61: Co, 7.43; N. 7.06: O. 16.14: Zn. 8.24 Found: C. 54.50; H. 6.65: Co. $7.39:$ N. $7.10:$ O. $16.20: \mathrm{Zn}, 8.20$. 
$(R, R)-N, N$-Bis(3,-tert-butylsalicylidene)-1,2-cyclohexanediamine $\mathrm{Co}-\mathrm{Co}\left(\mathrm{NO}_{3}\right)_{2}$ (h). The catalyst was synthesized as a similar procedure of the complex $f$ only with the substitution of $\mathrm{Co}\left(\mathrm{NO}_{3}\right)_{2} \cdot 6 \mathrm{H}_{2} \mathrm{O}$ for $\mathrm{Zn}\left(\mathrm{NO}_{3}\right)_{2} \cdot 6 \mathrm{H}_{2} \mathrm{O}$. The product $\mathbf{h}$ was obtained as a dark green solid. ${ }^{\mathrm{H}} \mathrm{H}-\mathrm{NMR}$ ( 400 MHz. DMSO-d 6 ): $\delta=1.24$ (s. 18H). $1.55 \cdot 1.68$ (m. 2H), 1.69 (s. $18 \mathrm{H}), 1.86-1.95(\mathrm{~m}, 2 \mathrm{H}), 1.96-2.20(\mathrm{~m}, 2 \mathrm{H}), 3.0-3.2(\mathrm{~m}$. $2 \mathrm{H}) .3 .5-3.8$ (m. $2 \mathrm{H}$ ). 7.40 (d. $J=2.4 \mathrm{~Hz}, 2 \mathrm{H}) .7 .59(\mathrm{~d}, J=$ 2.4 Hz. $2 \mathrm{H}), 7.74$ (s. $2 \mathrm{H}) .{ }^{13} \mathrm{C} \cdot \mathrm{NMR}(400 \mathrm{MHz}$. DMSO-d 6 ) $\delta$ $=24.3,25.1 .29 .530 .4 .31 .5,33.5 .35 .7 .66 .9,69.2 .118 .5$. 128.6. 129.0. 135.8. 141.6. 161.8. 164.4. FT-IR (KBr): $\left[\mathrm{cm}^{-1}\right]=2950.2863,1635.1608,1523.1461,1361,1253$. $1200.1172,1026,926,833.783,744.640 .597$ Anal. Cal. for $\mathrm{C}_{36} \mathrm{H}_{5} \mathrm{CO}_{2} \mathrm{~N}_{4} \mathrm{O}_{8}:$ C. 54.96; H. 6.66; Co. 14.98; N. 7.12: O. 16.27 Found C. 54.55: H. 6.67; Co, 15.00; N, 7.15: O. 16.30 .

(S)-ECH (Entry 1, Table 1). An oven dried $25 \mathrm{~mL}$ flask equipped with a stir bar was charged with $(R, R)$ catalysts a $(0.3 \mathrm{~mol} \%)$ and $( \pm)-\mathrm{ECH}(3.7 \mathrm{~g} .40 \mathrm{mmol} .1 .0$ equiv.) was stirred at open atmosphere at room temperature water bath. $\mathrm{H}_{2} \mathrm{O}(0.396 \mathrm{~g} .22 \mathrm{mmol}, 0.55$ equiv.) was added slowly. The reaction was mildly exothermic. The reaction mixture was allowed to stir for $5 \mathrm{~h}$. The optically pure product was isolated on Kugelrolu distillation (seal less tube oven Eyela KRDI00. Tokyo Rikakikai Co. Ltd.) into a $0{ }^{\circ} \mathrm{C}$ receiving flask. The recovered epoxide was followed filtration through a pad of $\mathrm{MgSO}_{4}$ to remove excess $\mathrm{H}_{2} \mathrm{O}$. An ee value $(>99 \%)$ of the recovered epoxide was determined to be Chiral GC $\left(\gamma\right.$-TA. $50^{\circ} \mathrm{C}$ isothermal. $[\alpha]_{\mathrm{D}}^{7(1)}+33.5\left(\mathrm{c}=1 . \mathrm{CH}_{3} \mathrm{OH}\right)$ and compared with commercially available standard product. ${ }^{1} \mathrm{H}$. ${ }^{13} \mathrm{C}$ NMR and elemental analysis confirmed the recovered epoxides.

(S)-Phenyl glycidyl ether (Entry 9, Table 1) \& (S)Styrene Oxide (Entry 10, Table 1). Synthesis procedure and analysis conditions followed by as mentioned above.

(S)-Glycidyl methyl ether (Entry 11, Table 1). An oven dried $25 \mathrm{~mL}$ flask equipped with a stir bar was charged with with $(R, R)$ catalysts a $(0.3 \mathrm{~mol} \%)$ and ( \pm -glycidyl methyl ether ( $3.524 \mathrm{~g} .40 \mathrm{mmol} .1 .0$ equiv.) was stirred under open atmosphere at room temperature water bath. $\mathrm{H}_{2} \mathrm{O}(0.396 \mathrm{~g}$. 22 mmol. 0.55 equiv.) was added drop wise. The reaction was mildly exothermic. The reaction mixture was allowed to stir for $3 \mathrm{~h}$. After reaction the recovered epoxide was treated with excess of aq. $\mathrm{HCl}(35 \%)$ and ring opened epoxide (1Chloro-3-phenoxy-propane-2-ol) was analyzed by Chiral GC analy'sis product obtained in $>99 \%$ ee (Chiraldex $\gamma$-TA. $60^{\circ} \mathrm{C}$ isothermal). The structure of products was confinned by ${ }^{1} \mathrm{H} .{ }^{13} \mathrm{C}$ NMR and elemental analysis.

General procedure for phenolic kinetic resolution (Table 2). In a representative reaction of ECH and phenol. with $(R, R)$ cataly'sts a $(1-2 \mathrm{~mol} \%)$, tert-butyl methyl ether (TBME) and ( \pm )-ECH (2.22 equiv.) were charged in an oven dried $25 \mathrm{~mL}$ flask and the reaction mixture was stirred in open atmosphere at ambient temperature. Phenol (1.0 equiv:) was added after complete dissolution of the catalyst. The resultant solution was stirred for $8 \mathrm{~h}$ and monitored by chiral GC and HPLC. The purification of the products was performed by flash column chromatography.

Butyl-p-hydroxyphenyl acetate. $p$-Hydroxyphenyl acetic acid $(5 \mathrm{~g} .0 .03 \mathrm{~mol})$ and $\mathrm{NaHSO}_{4}(0.2 \mathrm{~g})$ was dissolved in butyl alcohol $(50 \mathrm{~mL})$ at room temperature. A solution was refluxed and water removed through dean stark apparatus by azeotropic distillation. After completion of reaction. excess butyl alcohol was removed under reduced pressure offered oily turbid liquid purified by means of liquid column chromatography. Purification offered a colorless oily liquid $6.5 \mathrm{~g}(95 \%$ yields $)$.

${ }^{1} \mathrm{H}-\mathrm{NMR}\left(400 \mathrm{MHz}, \mathrm{CDCl}_{3}\right): \delta=0.96$ (t. $3 \mathrm{H}$ ). 1.22-1.68 $(\mathrm{m}, 4 \mathrm{H}) .3 .51$ (s, $2 \mathrm{H}), 4.1$ (t. $2 \mathrm{H}), 6.72-7.20(\mathrm{q}, 4 \mathrm{H}) .{ }^{13} \mathrm{C}-$ $\operatorname{NMR}\left(400 \mathrm{MHz}, \mathrm{CDCl}_{3}\right) \delta=13.6 .13 .7 .18 .8,19.0 .30 .4$, $34.6 .40 .5,62.7,64.8,115.4$. 125.5. 130.2. 155.2. 172.7. FTIR (neat): $\left[\mathrm{cm}^{-1}\right]=1740,3450$.

(S)-1-[p-[(Butoxycarbonyl) methyl] phenoxyl-3-chloropropane-2-ol. A solution of $( \pm)$-ECH $(0.98 \mathrm{~g} .0 .01 \mathrm{~mol}$, 2.22 equiv.). with $(R, R)$ catalysts a $(0.156 \mathrm{~g} .2 \mathrm{~mol} \%)$ dissolved in TBME and stirred for $15 \mathrm{~min}$ at room temperature followed by the drop wise addition of Butyl- $p$ hydroxyphenyl acetate ( $\mathrm{lg} .0 .004 \mathrm{~mol}$ ) in TBME for $5 \mathrm{~min}$. The reaction mixture was slightly warm and left for $8 \mathrm{~h}$ at room temperature under stirring. The reaction was monitored by TLC and the product was purified by flash column chromatography using silica gel to offer the colorless oil $1.25 \mathrm{~g}$. The enantiomeric excess $(e e)$ of the product is monitored by HPLC (OD-H- colunn). ${ }^{\text {H-NMR }}$ ( $400 \mathrm{MHz}$, $\left.\mathrm{CDCl}_{3}\right): \delta=0.96($ t. $3 \mathrm{H}), 1.22 \cdot 1.80(\mathrm{~m}, 4 \mathrm{H}) .2 .6(\mathrm{~d}, \mathrm{lH})$, $3.5 \mathrm{l}(\mathrm{s}, 2 \mathrm{H}), 3.7 \mathrm{l}(\mathrm{d} .2 \mathrm{H}) .4 .0-4.4(\mathrm{~m} .5 \mathrm{H}), 6.80-7.40$ (q, $4 \mathrm{H}) .{ }^{13} \mathrm{C}-\mathrm{NMR}\left(400 \mathrm{MHz}, \mathrm{CDCl}_{3}\right) \delta=13.6,19.0 .30 .5 .40 .4$, $45.9,64.7 .68 .5,69.8 .79 .5,114.6 .127 .1,130.3,157.2$, 171.8. FT-IR (neat): $\left[\mathrm{cm}^{-1}\right]=1730,3430$.

(S)-1-[p-[(Butoxycarbonyl) methyl] phenoxy]-3-(isopropylamino) propane-2-ol. The mixture of optically pure (S)-1-[p-[(Butoxycarbonyl) methyl] phenoxy]-3-chloropropane-2-ol $(1.0 \mathrm{~g}, 0.0033 \mathrm{~mol})$, isopropyl amine $(6 \mathrm{~mL})$ and water $(1 \mathrm{~mL})$ was refluxed for $3 \mathrm{~h}$. The reaction was monitored by TLC. Excess isopropyl anine was removed under reduced pressure. Residue was extracted by ethyl acetate. followed by the addition of water. The solvent was evaporated and crude product was recrystallized from hexane to give white crystals $0.80 \mathrm{~g}$ ( $74 \%$ yield).

${ }^{1} \mathrm{H}-\mathrm{NMR}(400 \mathrm{MHz}, \mathrm{CDCl}$ ) $: \delta=0.96(\mathrm{t}, 3 \mathrm{H}), 1.1(\mathrm{~d} .6 \mathrm{H})$, $1.22-1.80(\mathrm{~m} .4 \mathrm{H}), 2.4(\mathrm{~s}, 2 \mathrm{H}) .2 .7-2.9(\mathrm{~m} .3 \mathrm{H}), 3.5 \mathrm{l}(\mathrm{s} .2 \mathrm{H})$. $3.94 .2(\mathrm{~m} .5 \mathrm{H}), 6.80-7.40(\mathrm{q} .4 \mathrm{H}){ }^{13} \mathrm{C} \cdot \mathrm{NMR}(400 \mathrm{MHz}$, $\left.\mathrm{CDCl}_{3}\right) \delta=13.6,19.0,30.6,48.9,49.2,64.6,68.4,70.5$, 114.6, 126.6, 130.2. 157.7. 171.9.

(S)-Atenolol. An optically pure (S)-1-[ $p$-[(Butoxycarbonyl) methyl] phenoxy]-3-(isopropyl amino) propane-2-ol (0.5 g. $0.0015 \mathrm{~mol})$ dissolved in cold methanol $(3 \mathrm{~mL})$ and $\mathrm{NH}_{4} \mathrm{OH}(\mathrm{l} \mathrm{mL})$ was stirred at room temperature until TLC showed completion of reaction. The solvent was removed under reduced pressure to offer the crude atenolol. and it was purified by recrystallization from ethyl acetate to give a pure atenolol $0.30 \mathrm{~g}$ ( $73 \%$ yield).

${ }^{1} \mathrm{H}-\mathrm{NMR}\left(400 \mathrm{MHz}\right.$. $\left.\mathrm{D}_{2} \mathrm{O}\right): \delta=1.1$ (d. $6 \mathrm{H}_{3} J=2 \mathrm{~Hz}$ ), $2.81-$ $2.96(\mathrm{~m} .3 \mathrm{H}), 3.58(\mathrm{~s}, 2 \mathrm{H}) .4 .04-4.14(\mathrm{~m}, 3 \mathrm{H}), 7.01-7.30$ (q. 
$4 \mathrm{H}) .{ }^{13} \mathrm{C}-\mathrm{NMR}(400 \mathrm{MHz}, \mathrm{D}-\mathrm{O}) \delta=20.95 .20 .97 .41 .0,48.2$. $48.6,68.4 .70 .6 .114 .9 .115 .2,130.4$. 130.6, 157.4. 178.0 .

(S)-1-[p-(Cyanomethyl) phenoxy]-2,3-epoxypropane. A mixture of $( \pm)-1-[p$-(cyanomethyl) phenoxy]-2.3-eposypropane ( $1.0 \mathrm{~g}, 0.0053 \mathrm{~mol}, \mathrm{I}$ equiv). $(\boldsymbol{R}, \boldsymbol{R})$-catalyst a $(0.5$ mol\%) dissolved in THF and the nixture were stirred at room temperature. $\mathrm{H}_{2} \mathrm{O}(0.052 \mathrm{~g}, 0.55$ equiv) was added drop wise. The reaction was mildly exothernic. The reaction mixture was stirred up to occurrence of optically terminal epoxides and was checked periodically by HPLC using OD$\mathrm{H}$ Chiral column as well as TLC. After completion of reaction. the solvent was removed under reduced pressure. and epoxide was extracted by MC followed by addition of water. Yield of product was $45 \%(98 \%$ ee) on the basis of racenic epoxide. $\mathrm{H}-\mathrm{NMR}$ (400 $\mathrm{MHz} . \mathrm{CDCl}_{3}$ ): $\delta=2.71$ (dd. $1 \mathrm{H}, J=1.6 .3 .6 \mathrm{~Hz}) .2 .87(\mathrm{t}, \mathrm{lH} . J=4.4 \mathrm{~Hz}), 3.32(\mathrm{ml}, \mathrm{IH})$. 3.65 (s. $2 \mathrm{H}$ ), 3.92 (dd, IH. $J=5.6 \mathrm{~Hz}$ ). 4.22 (dd. $1 \mathrm{H}, J=2.4$. $2.8 \mathrm{~Hz}), 6.89$ (d. $2 \mathrm{H} J=8 \mathrm{~Hz}) .7 .2 \mathrm{l}$ (d, $2 \mathrm{H} J=8 \mathrm{~Hz}) .{ }^{13} \mathrm{C}$. NMR $\left(400 \mathrm{MHz}_{2} \mathrm{CDCl}_{3}\right) \delta=22.8 .44 .6 .50 .0 .68 .8,115.1$. 118.0. 122.3. 129.0. 158.0.

(S)-1-[p-(Cyanomethyl) phenoxy]-3-(isopropylamino) propane-2-ol. The mixture of an optically pure $(S)-1-[p-$ (cyanomethyl) phenoxy]-3-chloropropane-2-ol $(0.8 \mathrm{~g}$. $0.0035 \mathrm{~mol}$, lequiv). isopropyl amine $(6 \mathrm{~mL})$ and water $(\mathrm{l}$ $\mathrm{mL}$ ) was refluxed for $3 \mathrm{~h}$. The reaction was monitored by TLC. Excess isopropyl anine was removed under reduced pressure. Residue was extracted by ethyl acetate, followed by the addition of water. The solvent was evaporated and the crude product was recrystallized from hexane to give yellowish white cry stals $0.62 \mathrm{~g}$ (70\% yield). ${ }^{1} \mathrm{H}-\mathrm{NMR}(400$ $\mathrm{MHz} \mathrm{CDCl}_{3}$ ): $\delta=1.1$ (s. $6 \mathrm{H}$ ), 2.7 (n. $1 \mathrm{H}$ ), 2.9 (d. $2 \mathrm{H}$ ), 3.67 (s. 2H), 3.9-4.2 (m, 3H). 6.80-7.40 (q. 4H). ${ }^{13} \mathrm{C}-\mathrm{NMR}(400$ $\left.\mathrm{MHz} \mathrm{CDCl}_{3}\right) \delta=22.8 .23 .0 .23 .1,48.8 .49 .2 .68 .3,68.9$. $70.6,115,0,118.0,121.9,128.9,129.158 .3$

(S)-(-)-3,4-Dihydroxybutanoate methyl ester. A solution of $( \pm)$-methyl-4-oxobutanoate (l g. $0.0086 \mathrm{~mol}$. 1 equiv) in $2 \mathrm{~mL}$ THF and $(S, S)$-catalyst a $(2.54 \mathrm{mg} .0 \mathrm{~mol} \%)$ was stirred for $10 \mathrm{~min}$ at room temperature in $25 \mathrm{~mL}$ round bottom flask. The flask was cooled to $5^{\circ} \mathrm{C}$ and $\mathrm{H}_{2} \mathrm{O}(0.09 \mathrm{~g}$. 0.55 equiv) was added in one portion. The reaction was allowed to warm up room temperature and stirred for $12 \mathrm{~h}$. The reaction monitored by $\mathrm{GC}$ indicated that diol was presented in $50 \%$ yield. Hexane was added and filtered to remove the cataly st. The residue was stirred with the mixture of water and ethyl acetate (1:1 vol. ratio). The ethyl acetate layer was collected and dried with $\mathrm{Na}_{2} \mathrm{SO}_{4}$. and then concentrated in vano. The residue was purified by flash column with MC:Methanol (80:20). The optical purity determined with chiral $\gamma$ TA column was $99 \%$ ee. ${ }^{\text {H}} \mathrm{H}-\mathrm{NMR}$ $\left(400 \mathrm{MHz} . \mathrm{CDCl}_{3}\right): \delta=2.50$ (dd, $2 \mathrm{H} . J=12,8 \mathrm{~Hz}$ ). 3.52 (n. lH), 3.63-3.76 (m. IH) overlapping with $3.70(\mathrm{~s}, 3 \mathrm{H}) .4 .10$ (m. 1H) ${ }^{13} \mathrm{C} \cdot \mathrm{NMR}\left(400 \mathrm{MHz} . \mathrm{CDCl}_{3}\right) \delta=35.9,37.5,51.9$. $52.5,65.6 .68 .5,172.7$.

(S)- $\beta$-Hydroxy- $\gamma$-butyrolactone. An optically pure (S)- (-)3.4-dihydroxybutanoate methyl ester was dissolved in 5 $\mathrm{mL} \mathrm{MC}$ and catalytic amount of $\mathrm{CF}_{3} \mathrm{COOH}$ was added, and it was refluxed for $12 \mathrm{~h}$. After completion of reaction, the solvent was removed under reduced pressure and the product was purified through column chromatography. The optical purity determined by chiral $\gamma$-TA column indicated $98 \%$ ee. ${ }^{l} \mathrm{H}-\mathrm{NMR}\left(400 \mathrm{MHz} . \mathrm{CDCl}_{3}\right.$ ): $\delta=2.28$ (dd, IH. $J=$ 16.4. $1.2 \mathrm{~Hz}$ ), 2.59-2.65 (dd. $1 \mathrm{H}, J=6.0,6.0 \mathrm{~Hz}$ ). $4.11-4.14$ (dd. IH) $4.25-4.29$ (dd, IH). 4.5 (dd. 1H). ${ }^{13}$ C-NMR (400 $\left.\mathrm{MHz}, \mathrm{CDCl}_{3}\right) \delta=37.4,66.9 .76 .2,177.3$.

Acknowledgement. This work was supported by Inha University Research Grant.

\section{References}

1. Tokunaga, M.; Lamow, J. F; Kakiuchi, F.: Jacobsen, E. N. Science 1997. 277.936. (b) Furrow, M. E.: Schaus, S. E.: Jacobsen, E. N. J. Org. Chem, 1998. 63.6776. (c) Ready. T. M. Jacobsen. E. N. An. Chen. Soc. 1999. 121.6068.

2. Li. W.: Thakur. S. S.: Chen. S.-W: Shin. C. K.: Kawthekar. R. B.: Kim. G.J. Tetrahedron Lett. 2006. 47. 3453. (b) Chen. S. W: Thakur. S. S.; Li. W.: Shin, C. K.: Kawthekar, R. B.: Kim. G.-J. J. 1fol. Cat. A: Chemical 2006. 259. 116 . (c) Chen, S.W: Kawthekar. R. B.: Kim. G.-J. Tetrahedron Lett. 2007. 48. 297. (d) Lee. K.-Y.: Kawthekar. R. B.: Kin. G.-I. Bull Korem Chent. Soc. 2007. 28. 1553

3. Shibasaki. M.: Kanai. M.: Funabashi. K. Chent Commm 2002. 1989. (b) Shibasaki, M: Yoshikawa, N. Chem. Rev 2002. 102. 2187. (c) Iida. T; Yamamoto, N.; Matsunaga. S.: Woo, H.-G: Shibasaki, M. Angew! Chem. Int Ed. 1998, 37, 2223. (d) Matsunaga, S.: Yoshida. T.: Morimoto. H.: Kumagai. N.: Shibasaki. M. J . Ant. Chent. Soc. 2004. 126. 8777. (e) Handa. S.: Gnanadesikan. V: Matsul1aga. S.: Shibasaki. M. J. Ant. Chent. Soc. 2007. 129.4901.

4. Gruber. S. J.: Harris, C. M.: Sinn, E. The J. Chem. Phy 1968. 49. 2183. (b) Gruber, S. J.; Harris. C. M.: Sinn. E. horg. Chem. 1968. 7. 268. (c) Gruber. S. J.; Harris, C.: Harris, M.; Sinn, E. horg. \& Nuc. Chem. Letl. 1967. 3. 495.

5. Thakur. S. S.: Chen. S.-W: Li. W.: Shin. C. K: Kimn. S.-T.: Koo. Y.M.: Kim. G.-T. J. Onganomet. Chem 2006. 691. 1862

6. Uchikawa, O:- Okukado. N.; Sakata. T: Arase. K: Terade, K. Bull. Chem. Soc. Jpn. 1988, 61,2015.

7. Bevinakatti, H. S.; Banerji, A. A. J. Org. Chem. 1992, 57. 6001 .

8. Akisanya. T.: Parkins. A. W.: Steed. J. W. Org. Proc. Res \& Dev: 1998. 2. 274 .

9. Bose. D. S.: Narsaiah. A. V. Bioorg \& Med Chem. 2005.13. 627.

10. Bartoli, G: Bosco. M: Carlon, A.: Locatelli, M.: Melchorre. P: Sambri. L. Org. Lett. 2004. 6, 3973.

11. (a) Lu. X. B.: Liang. B.: Zhang. Y. T.: Tian1. Y. Z.: Wang. Y. M.: Wang. H.: Zhang. R. J. Am. Chent Soc. 2004. 126. 3732. (b) Lu. X. B.: Shi. L.: Wang. Y. M.: Zhang. R.: Zhang. Y. T.: Peng. X. J.: Zang. Z. C.: Li. B. J.Am. Chem. Soc. 2006, 128,1664

12. Berkessel, A.: Bradenburg, M. Org. Lett. 2006, $20,4401$.

13. Burk. R. M.: Roof, M. B. Tetrahedron Lett. 1993. 34, 395

14. Matsumoto. K.: Fuwa. S.: Kitajima. H. Tetrahedon Lett. 1995 36. 6499 .

15. Shen. Y. M.: Duan. W.: Shi. L. M. J. Org. Chent 2003. 68. 1559.

16. (a) Paddock, R. L: Nguven. S. T. J. Am. Chem. Soc. 2001. 123. 11498. (b) Paddock. R. L.: Nguven. S. T. Chem. Commm. 2004. 1622. 